\title{
The Effect of Annealing Treatments on Spherulitic Morphology and Physical Ageing on Glass Transition of Poly Lactic Acid (PLLA)
}

\author{
El-Hadi Ahmed Mohamed ${ }^{1,2}$ \\ ${ }^{1}$ Department of physics, Faculty of Applied Science, Umm al-Qura University, Mecca, Kingdom of Saudi Arabia; ${ }^{2}$ Department of \\ Basic Science, Higher Institute for Engineering and Technology, El Arisch, Nord Sinai, Egypt. \\ Email: Bioplastics.elhadi1962@yahoo.com
}

Received October $29^{\text {th }}, 2010$; revised December $24^{\text {th }}, 2010$; accepted May $9^{\text {th }}, 2011$.

\begin{abstract}
Spherulitic morphology of pure poly lactic acid (PLLA) PLLA have investigated after thermal annealing. The morphology of spherulite of pure poly lactic acid (PLLA) PLLA have investigated after thermal annealing. The effect of both annealing temperature and crystallization temperature on the formation of cracks was described by polarized optical microscope (POM). Non banded spherulite (fibrils) with cracks was detected in PLLA film after annealing at $160^{\circ} \mathrm{C}$ (180 min.) and isothermal crystallization temperatures at $140^{\circ} \mathrm{C}$ and $150^{\circ} \mathrm{C}$. With increasing temperature after annealing treatment the size of spherulite is increased and more cracks are formed. The maximum growth rate of spherulites was found at $130^{\circ} \mathrm{C}$. The physical ageing was carried out by annealing the PLLA sample at room temperature for several annealing time $\left(t_{a}\right)$ from $0 \mathrm{~h}$ to $720 \mathrm{~h}$. The enthalpy relaxation has been studied by differential scanning calorimetry (DSC) through analysis of the endothermic peak of glass transition temperature, which increased and shifted towards higher temperature as the annealing time increased.
\end{abstract}

Keywords: Poly Lactic Acid (PLLA), Morphology, Non-Banded Spherulites, Annealing, Polarized Optical Microscopy, Physical Ageing

\section{Introduction}

Most of the plastic materials from petrochemicals such as polyethylene (PE), polypropylene (PP), poly vinyl chloride (PVC) and polystyrene (PS) are used in various areas, such as household appliances, auto parts, building materials and packaging of food, because of their excellent processing, physical properties and durability. However there is a problem with the disposal of these products. It is making many environmental problems (pollution), such as the disposal of municipal solid waste by burning. It leads to the rise of toxic gases associated with rising temperature and increase in the concentration of carbon dioxide in the atmosphere.

The last twenty years attracted the attention of many scientists to this problem and they have been looking at the production of bioplastics materials called green polymers or environment polymers. The most important of these new materials are poly(3-hydroxybutyrate) (PHB) [1-3] and poly lactic acid (PLLA). PLLA [4] is polyester aliphatic, insoluble in water, biodegradable thermo plastic and transparent.

PLLA has a crystallinity of about $40 \%$, glass transition temperature of $50^{\circ} \mathrm{C}-70^{\circ} \mathrm{C}$ and melting temperature of $173^{\circ} \mathrm{C}-178^{\circ} \mathrm{C}$. Although the lactic acid has been known for more than a century. Its scientific and commercial interest has increased only in recent years around the world because of environmental pollution. Now, it is the next generations alternative to synthetic polymers from petrochemicals. Lactic acid can produce from renewable resources (molasses from sugar cane and syrup date) using bacterial fermentation (micro-organisms, bacteria), remnants of food and dairy plants. PLLA can be used as sutures and bone implants (screws, pins, plates, fixation rods and clips, etc), pharmaceutical, cosmetic, textiles industries and food packaging applications, shopping bags, especially for deep drawing articles, thermoformed products such as drinking cups, take-away food trays, containers and plant boxes and diapers [4].

Advantages: PLLA is biodegradable and insoluble in 
water, polyester, optics actives, crystalline and higher melting temperature [4-11].

Disadvantages: PLLA is brittle, higher cost of production, poor mechanical properties and slow crystallization rate [8-11], compared to synthetic polymers like polystyrene (PS), polypropylene (PP) and polyethylene terephthalate (PET).

It is known that semi-crystalline polymers can form spherulites when crystallized from solution or melts. The morphology of PLLA is mainly spherulitic. The spherulites made of thin fibrils are oriented along the radius of a circle. With increasing the crystallization time, the spherulites grow and impinge with each other longitudinally.

The study of thermal stability and morphology is important [12-17] in polymer processing because control the temperature of the end product during the processing like injection molding or casting film by chill roll is necessary. The physical properties of semi-crystalline polymers depend upon the mechanisms of crystallization and morphology during processing. Mechanisms of crystallization is the key to the basic information for understanding the relationship between manufacturing processes and features observed in the final product of the polymer.

It is important to study the physical aging [18] to design and develop the polymers with long term durability, i.e. understand the safe use of polymers. The aging process is common in non-crystalline polymer and referred to as structural relaxation and is happening because these materials do not exist in the state of thermodynamic equi- librium. Physical aging is a phenomenon that is caused by material evolution towards thermodynamic equilibrium. Physical ageing is called change in amorphous phase by annealed at different temperature $\left(T_{a}\right)$ at near or lower than its glass temperature $\left(T_{g}\right)$. This leads to changing in physical properties such as density, enthalpy, dielectric permittivity, electrical conductivity and refractive index, also make changes in the mechanical properties like Young's modulus and yield stress. This occurs during longer storage time by use of polymers.

The aim of present work is to investigate the effect of annealing treatments on the morphology of PLLA using polarized optical microscopy (POM). Furthermore, the physical ageing phenomenon and the glass transition temperature were studied using differential scanning calorimetry (DSC).

The aim of this study is to investigate the effect of annealing treatments of PLLA on morphology using polarized optical microscopy (POM) and the physical ageing phenomenon on the glass transition temperature using differential scanning calorimetry (DSC).

\section{Experimental}

Poly (L-Lactic acid) PLLA, grade L9000 was obtained from Biomer ${ }^{\circledR}$, Germany. PLLA had initially a molar mass of $220000 \mathrm{~g} / \mathrm{mol}$.

PLLA as pellet was prepared by dissolving in hot chloroform $(0.04 \mathrm{~g} / \mathrm{ml})$, and then the solution was casted on microscopy glass slide as a thin film $(100-300 \mathrm{~nm})$. The casting films held for 24 hour to evaporate the solvent and dried at $60^{\circ} \mathrm{C}$ for 1 day to remove the solvent completely. The casted film with glass slide was covered with another glass slide. The casted film was placed between two microscopy glass slide as a sandwich and inserted to a hot stage and melted at $200^{\circ} \mathrm{C}$ for $3 \mathrm{~min}$ to erase their thermal history and cooled slowly to the isothermal crystallization temperature $\left(T_{c}\right)$. The sample was held at both $\left(T_{a}\right)$ and $\left(T_{c}\right)$ for the required time to develop spherulite.

The morphology of PLLA was studied by optical microscopy (Nikon Eclipse E600) equipped with hot-stage (Instec STC200). The sample was heated on the hot-stage from room temperature to $200^{\circ} \mathrm{C}$, held $3 \mathrm{~min}$. for complete melting of the polymer, and cooled slowly from $200^{\circ} \mathrm{C}$ to annealing temperature $\left(T_{a}=160^{\circ} \mathrm{C}\right)$ and isothermal crystallization $T_{c}$ of $140^{\circ} \mathrm{C}$ and $150^{\circ} \mathrm{C}$ where the growing of spherulites started. A new sample was used each time to keep away from any effects due to degradation processing by higher melting processing temperature $\left(T_{m p}=200^{\circ} \mathrm{C}\right)$.

Glass transition temperature $\left(T_{g}\right)$, heat capacity $\left(C_{p}\right)$ and enthalpy of relaxation $(\Delta H)$ are determined by differential scanning calorimetry (DSC). The sample was heated from room temperature to $200^{\circ} \mathrm{C}$ with the a rate of $10^{\circ} \mathrm{C} \cdot \mathrm{min}^{-1}$ and kept at ageing times $24 \mathrm{~h}, 48 \mathrm{~h}, 96 \mathrm{~h}$ and $720 \mathrm{~h}$ (first run). Whereas in the second run, the samples were heated from $25^{\circ} \mathrm{C}$ to $80^{\circ} \mathrm{C}$ with a rate of $10^{\circ} \mathrm{C} \cdot \mathrm{min}^{-1}$ (second run). The enthalpy of relaxation was seen as an endotherm near $T_{g}$.

\section{Results and Discussion}

\subsection{Morphology and Spherulite Growth Rate}

Spherulitic textures are morphological features. It observed in semi crystalline polymers. A generation of spherulite started from lamellar crystal, which is often formed at the beginning of the crystal flakes (nucleation). Moreover, spherulite can be formed in two or three dimensions (spherical), crystal circular that displays in maltese cross between polaroids (polarizer and analyzer). Figure 1 is shown the polarized optical micrographs of neat PLLA spherulites with cracks. These cracks depend on the crystallization temperature $\left(T_{c}\right)$ and the annealing temperature $\left(T_{a}\right)$. Cracks appear after melting, annealing 


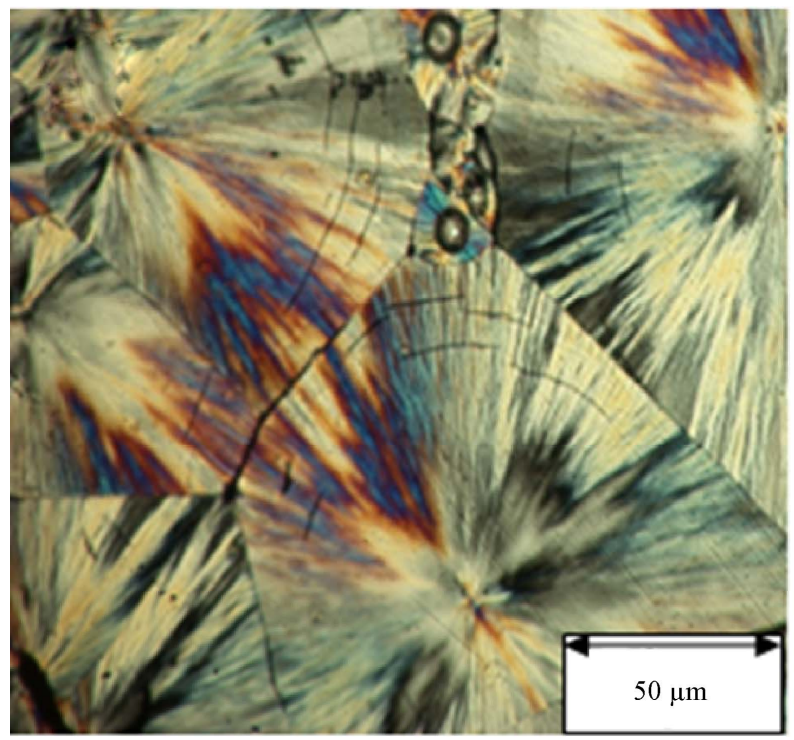

(a)

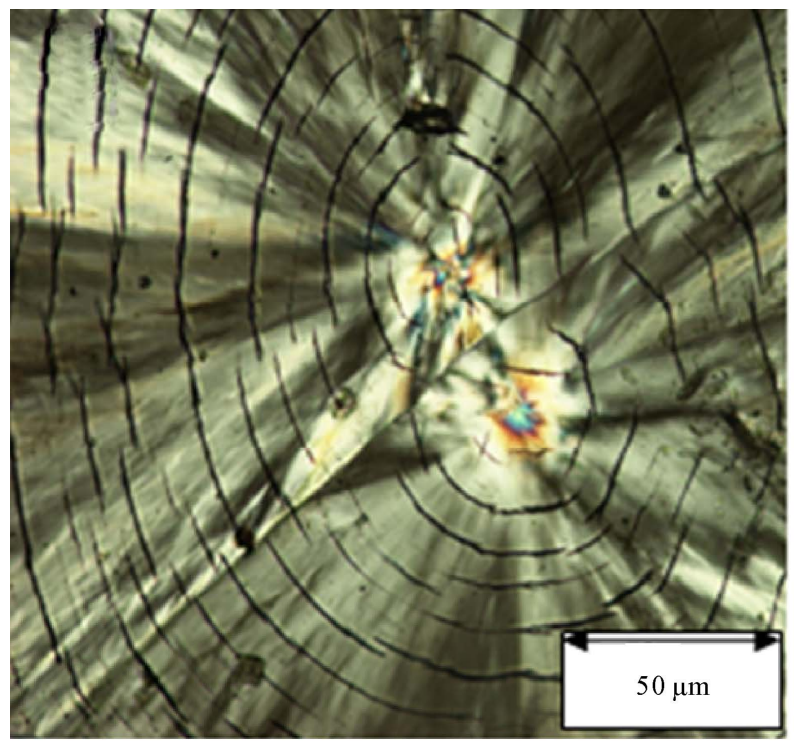

(b)

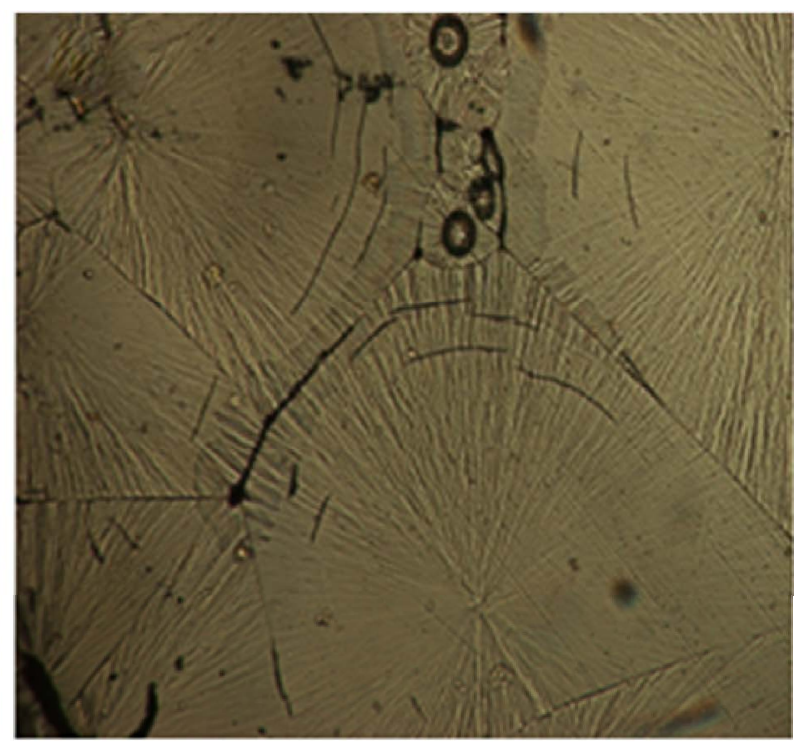

$\left(a^{\prime}\right)$

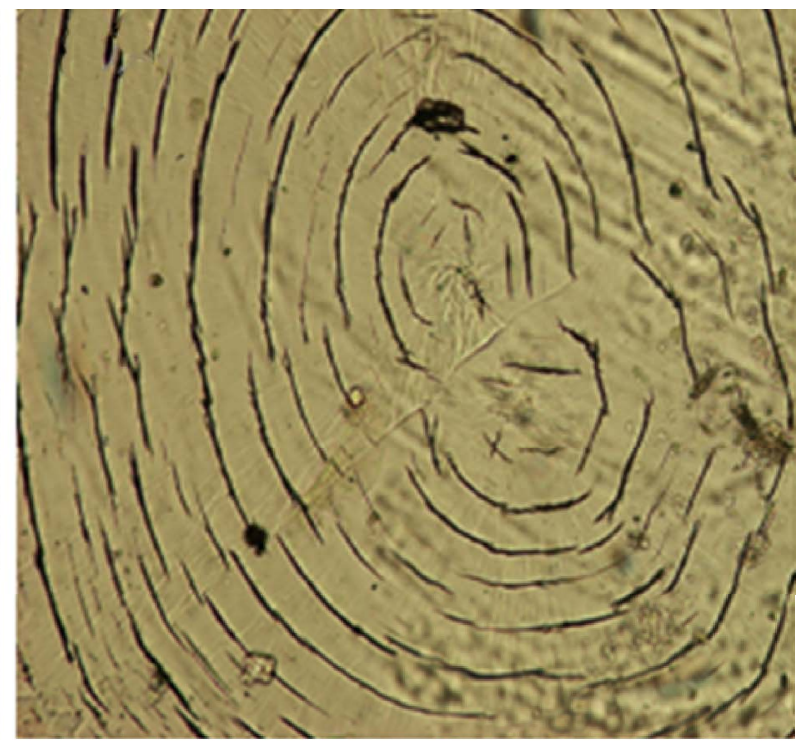

(b')

Figure 1. Optical microscopy images of the crystallizations of PLLA after annealing for 180 min. and isothermal crystallization with optical polarizer at (a) $140^{\circ} \mathrm{C}$, (b) $150^{\circ} \mathrm{C}$; without optical polarizer (a'), (b'). The scale bar measures $50 \mu \mathrm{m}$.

temperature and then the crystallization temperature. We have seen in Figures 1(a), (a') few cracks at the crystallization temperature of $140^{\circ} \mathrm{C}$. By increasing the crystallization temperature to $150^{\circ} \mathrm{C}$ in Figures $1(\mathbf{b}),\left(\mathbf{b}^{\prime}\right)$, this leads to an increase the number of the cracks. These cracks did not appear in the crystallization process without annealing. Same results found in poly(3-hydroxybutyrate) PHB [3]. Keller and Hobbs [19] found large spherulites with cracks and splitting around the center circular in PHB spherulite. They attributed the formation of cracks due to the cooling and difference in coefficients of thermal expansion between the plastic film and glass slides.

It is important to measure spherulite growth rates of PLLA in the range from $90^{\circ} \mathrm{C}$ to $150^{\circ} \mathrm{C}$. The radial growth rate of the spherulite was determined by monitoring the spherulite radius $\mathrm{R}$ as a function of time during isothermal crystallization in the hot-stage of a polarizing microscope. The curve of growth rate of spherulite as shown in Figure 2 shows clearly that the maximum spherulite growth rate of PLLA is at $130^{\circ} \mathrm{C}$. The decrease in spherulite diameter is due to reduction in the crystalli- 


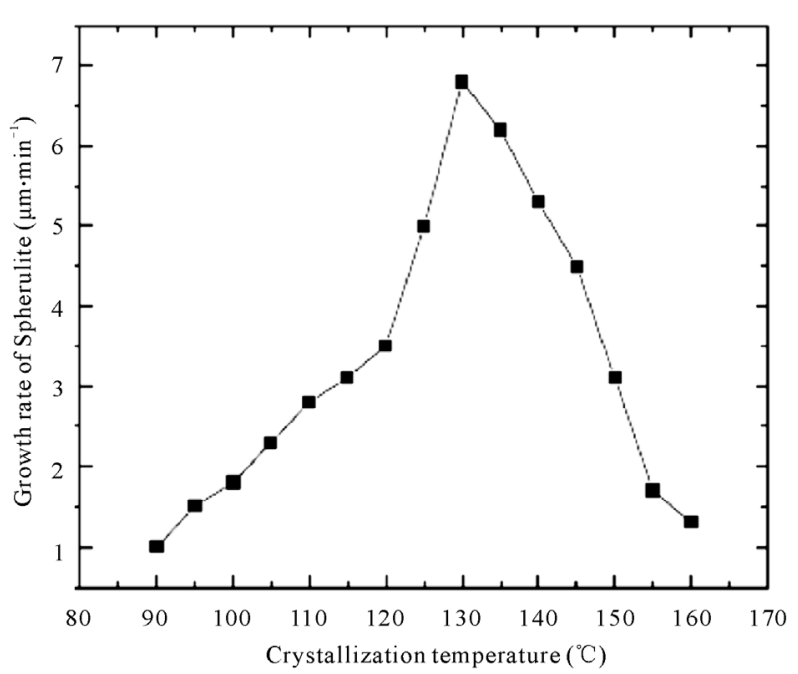

Figure 2. Spherulite growth rates of PLLA, isothermal crystallization after cooling from the melt as a function of temperature.

zation temperature. The sharp peak at crystallization temperature of $120^{\circ} \mathrm{C}$ is similar to the results reported in Refences $[14,16]$. It was also found that the crystallization kinetics of the investigated PLLA is very slow. This is due to the fact that the number of homogenous nucleated is small at temperatures more than $130^{\circ} \mathrm{C}$, which causing longer time period at the processing. We found that the crystallization kinetics of the PLLA is very slow because the number of homogenous nucleation are small at more than $130^{\circ} \mathrm{C}$, causing longer time period at the processing. This means that the spherulites are large and make the material more brittle.

\subsection{DSC Analysis}

Physical aging in polymers can occurs at deferent time at room temperatures below the glass transition temperature $\left(T_{g}\right)$. DSC thermograms were recorded on heating as a function of aging time $\left(t_{a}\right)$. Figure 3 shows the relation between heat flow and temperature. It was shown that, the glass transition temperature $\left(T_{g}\right)$ of pure PLLA appeared at $60^{\circ} \mathrm{C}$, cold crystallization $\left(T_{c c}\right)$ at $108^{\circ} \mathrm{C}$, melting point $\left(T_{m}\right)$ at $174^{\circ} \mathrm{C}$. Figure 4 shows DSC curves for the PLLA samples with different ageing time and the glass transition temperature was determined. The result the ageing of PLLA has also strong influence on the glass transition temperature. The enthalpy relaxation was found to be increase with ageing time and the glass transition shifted to a higher temperature. At beginning, the value of $T_{g}$ found to be $61^{\circ} \mathrm{C}$ after $24 \mathrm{~h}$ and $96 \mathrm{~h}$, it increased to $62.5^{\circ} \mathrm{C}$ after 15 and 30 days.

\section{Conclusion}

The effect of annealing after melting on morphology of

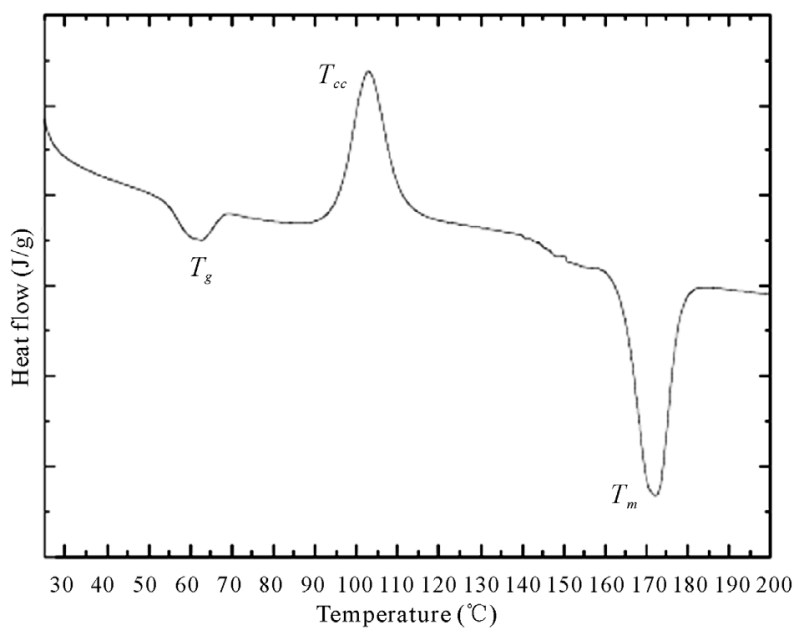

Figure 3. DSC second heating of PLLA after annealing at room temperature for $360 \mathrm{~h}$.

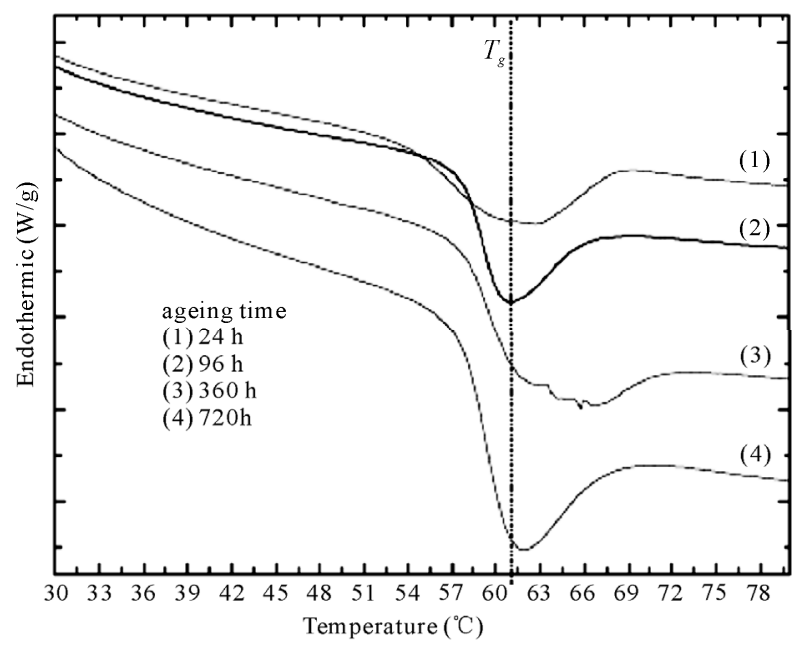

Figure 4. Enthalpy relaxation of the PLLA samples with heating rate $10^{\circ} \mathrm{C} \cdot \mathrm{min}^{-1}$ after ageing time: (a) $24 \mathrm{~h}$; (b) $96 \mathrm{~h}$; (c) $360 \mathrm{~h}$; and (d) $720 \mathrm{~h}$.

pure PLLA by POM has been discussed. Large non banded spherulites with cracks are formed around the center after annealed at higher temperature by longer annealing time and isothermal crystallization. Changes of relaxation enthalpy were detected by DSC after annealing near glass transition temperature $\left(T_{g}\right)$. The position of glass transition shifted to higher values and magnitude of the enthalpy increased by increasing the ageing time.

\section{Acknowledgements}

The author thanks the research and consulting center and institute of scientific research for part supporting this project 43005001 (ministry of higher education of K.S.A). 


\section{REFERENCES}

[1] A. El-Hadi and R. Schnabel, "Effect of Melt Processing on Crystallization Behavior and Rheology of Poly(3-hydro-xybutyrate) (PHB) and Its Blends," Macromolecular Materials and Engineering, Vol. 287, No. 5, 2002, pp. 363-372. doi:10.1002/1439-2054(20020501)287:5<363::AID-MA ME363>3.0.CO;2-D

[2] A. El-Hadi and R. Schnabel, "Correlation between Degree of Crystallinity, Morphology, Glass Temperature, Mechanical Properties and Biodegradation of Poly (3-hydroxyal-kanoate) PHAs and Their Blends," Polymer Test, Vol. 21, No. 6, 2002, pp. 665-674. doi:10.1016/S0142-9418(01)00142-8

[3] A. El-Hadi, "Development of a Biodegradable Material Based on Poly(3-hydroxybutyrate) PHB," Ph.D. Dissertation, Physics Department, University of Halle-Wittenberg, Halle and Wittenberg, 2002.

[4] Y. Ikada and H. Tsuji, "Biodegradable Polyesters for Medical and Ecological Applications," Macromolecules Rapid Communication, Vol. 21, No. 3, 2000, pp. 117-132.

[5] S. Petrulyte, "Advanced Textile Materials and Biopolymers in Wound Management," Danish Medical Bulletin, Vol. 55, No. 1, 2008, pp. 72-77.

[6] W. H. Hoidy, M. B. Ahmad, E. A. J. Al-Mulla and N. A. B. Ibrahim, "Preparation and Characterization of Polylactic Acid and Polycaprolactone Clay Nanocomposites," Journal of Applied Sciences, Vol. 10, No. 2, 2010, pp. 97106. doi:10.3923/jas.2010.97.106

[7] Z. Kulinski and E. Piorkowska, "Plasticization of Poly(L-lactide) with Poly(propylene glycol)," Biomacromolecules, Vol. 7, No. 20, September 2006, pp. 21282135. doi: $10.1021 / \mathrm{bm} 060089 \mathrm{~m}$

[8] R. Masirek, E. Piórkowska, A. Gałęski and M. Mucha, "Influence of Thermal history on the Nonisothermal Crystallization of Poly(L-lactide)," Journal Applied Polymer Science, Vol. 105, No. 1, 2007, pp. 282-290. doi:10.1002/app.26047
[9] M. Kozłowski, R. Masirek, E. Piórkowska and M. Gazicki- Lipman, "Biodegradable Blends of Poly(L-lactide) and Starch," Journal Applied Polymer Science, Vol. 105, No. 1, 2007, pp. 269-277. doi:10.1002/app.26088

[10] M. Pluta and A. Gałeski, "Plastic Deformation of Amorphous Poly(L/DL-lactide), Structure Evolution and Physical Prorties," Biomacromolecules, Vol. 8, No. 6 2007, pp. 1836-843. doi:10.1021/bm061229v

[11] M. Pluta, "Melt Compounding of Polylactide/Organoclay: Structure and Properties of Nanocomposites," Journal Polymer Science B: Polymer Physics, Vol. 44, No. 23, 2006, 3392-3405. doi:10.1002/polb.20957

[12] H. D. Keith and F. J. Padden, "The Optical Behavior of Spherulites in Crystalline Polymers, Part I, "Calculation of Theoretical Extinction Patterns in Spherulites with Twisting Crystalline Orientation," Journal Polymer Science, Vol. 39, No. 135, 1959, pp. 101-122.

[13] A. J. Lovinger and D. C. Bassett, "Development in Crystalline Polymers-1, Chapter 5," Applied Science Publishers, 1982, pp. 195-273.

[14] M. L. Di Lorenzo, "Crystallization Behavior of Poly(L-lactic acid)," European Polymer Journal, Vol. 41, No. 3, 2005, pp. 569-575. doi:10.1016/j.eurpolymj.2004.10.020

[15] R. Vasanthakumari and A. J. Pennings, "Crystallisation Kinetics of Poly(L-lactic acid)," Polymer, Vol. 24, No. 2, 1983, pp. 175-178. doi:10.1016/0032-3861(83)90129-5

[16] Y. Yuryev, P. Wood-Adams and M. C. Heuzey, "Crystallization of Polylactide Films: An Atomic Force Microscopy Study of the Effects of Temperature and Blending," Polymer, Vol. 49, No. 9, 2008, pp. 2306-2320. doi:10.1016/j.polymer.2008.02.023

[17] L. C. E. Struik, "Mechanical Behavior and Physical Ageing of Semi-Crystalline Polymers," Polymer, Vol. 30, No. 5, 1989, pp. 815-830. doi:10.1016/0032-3861(89)90177-8

[18] J. K. Hobbs, T. J. McMaster, M. J. Miles and P. J. Barham, "Cracking in Spherulites of Poly(hydroxybutyrate)," Journal Polymer Science Part B: Polymer Physics, Vol. 37, No. 15, 1996, pp. 3241-3246. 